\title{
A model and empirical test of information technology strategy success
}

\section{Mohammad Kazem Haki}

Faculty of Business and Economics, Institute of Information Systems,

Universite de Lausanne,

Quartier UNIL-Dorigny, Batiment Internef,

1015 Lausanne, Internef, Bureau 139, Switzerland

E-mail: kazem.haki@unil.ch

\begin{abstract}
Organisations are looking for IT solutions to propel their business, and meet the needs of an overly competitive landscape. Successful implementation of a sound IT strategy, then, is the key. Strategic use of IT and alignment with business strategies can be achieved only by developing a successful information technology strategy (ITS). A successful ITS has consequently become a vital part of strategic thinking in organisations. Despite the growing number of IT strategic planning frameworks proposed, organisations still fail. The main reason for this failure is organisations' tendency to emphasise the technical and technological aspects while neglecting the organisational (non-technical) factors of IT strategy. In this paper, we will identify the main organisational factors-related to successful implementation of ITS and ultimately, the organisation's success in the marketplace.
\end{abstract}

Keywords: organisational factors; information technology strategy; ITS; information technology/information systems strategic planning; IT/ISSP; change management; structural equation model; SEM.

Reference to this paper should be made as follows: Haki, M.K. (2011) 'A model and empirical test of information technology strategy success', Int. J. Information Systems and Change Management, Vol. 5, No. 1, pp.54-75.

Biographical notes: Mohammad Kazem Haki is a Doctoral student in the Institute of Information Systems at University of Lausanne. He obtained his MS in IT Management from University of Tehran, Iran. His research interests include service-oriented architecture (SOA), enterprise architecture (EA) and IT strategy.

\section{Introduction}

There exist three major roles for IT management:

a administrative

b operational

c competitive. 
The administrative role signifies the scope of IT as the automation of accounting and control functions, which is reasonably well understood in conventional literature on management information systems (IS). The operations role is an extension of the first role, but is distinguished by the creation and deployment of a technology platform that creates the capability to automate the entire set of business processes as opposed to only the administrative activities. In contrast, the competitive role represents a significant point of departure whereby it leverages the information and technological attributes in order to obtain a competitive advantage in the marketplace (Ho, 1996).

According to the change of information technology's role from operational to strategic level, information technology/information systems strategic planning (IT/ISSP) has been identified as a vital process in integrating IT into organisations so as to promote organisational success and competitiveness (Lee and Bai, 2003). Therefore, the strategic use of IT, or constructing and employing the competitive role of IT, first requires the development of an effective IS/IT strategic plan.

\subsection{Information technology/information systems strategic planning}

The field of IT/ISSP utilises many common terms such as: strategic information systems planning (SISP), information systems planning (ISP), information systems strategic planning (ISSP) and business systems planning (BSP). Research and experience illustrates that all of these terms are interchangeable (Ward and Peppard, 2002).

Lederer and Sethi (1996) defined ISSP as "the process of identifying a portfolio of computer-based applications that will assist an organisation in executing its business plans and consequently realising its business goals”. IS planning has been described as a managerial process for integrating IS considerations into corporative planning processes, linking IS applications to business goals, and determining information requirements necessary for meeting an organisation's short- and long-term objectives (Wang and Tai, 2003). ISP can be also referred to as a process of searching for strategic IS applications that enable an organisation to develop a competitive advantage rather than simply maintaining its position (Turban et al., 2003). The result of IT/ISSP is an accurate action plan detailing the desired course of events necessary to align information use and needs with the strategic direction of the company (Battaglia, 1991).

According to a survey conducted by Teo and Ang (2000), the reasons for using the IT/ISSP process are to: support business objectives better, improve system integration, exploit IT for competitive advantage, prioritise IS development projects, improve top management support for IS functions, facilitate better system investment decisions, and improve resource allocation, among other things.

IT/IS strategic planning has been identified as essential in integrating IT into an organisation to increase a firm's strategic competitive advantage (Bai and Lee, 2003). According to surveys on IS management issues, IT/ISSP remains one of the top issues facing corporate general managers and IS executives (Niederman et al., 1991; Brancheau et al., 1996; Watson et al., 1997; Gottschalk, 2001).

The IT/ISSP process involves a long range planning horizon for funds, human services, technical expertise, hardware and software capabilities needed to take advantage of any opportunities that may arise (Baker, 1995; Basu et al., 2002) during implementation. 
Lederer and Sethi (1996) indicate that improper IT/ISSP implementation might fail to realise the anticipated benefits of IT/IS investments; ultimately leading to incomplete system projects and resulting in incompatible, redundant and inflexible IS. In contrast, a superior IT/ISSP process produces a better plan (Bai and Lee, 2003). In short, SISP serves an important management function.

In this paper, we consider the success of IT/ISSP. Lederer and Sethi (1996) proposed two measures for assessing the success of IT/ISSP. One measure of planning success is the fulfilment of objectives which includes aligning IT with the business, gaining competitive advantage, identifying new and higher payback applications, identifying strategic applications, increasing top management commitment, improving communications with users, forecasting IT resource requirements, allocating IT resources, developing an information architecture, and increasing the visibility of IT. Another measure is planner satisfaction.

Segars and Grover (1998) developed four approaches for assessing the effectiveness of IT strategic planning which are 'goal-centred judgement' (to assess the degree of attainment in relation to targets), 'comparative judgement' (compares the effectiveness of a particular system with other similar systems), 'normative judgement' (compares to 'standards of the field' rather than the unique planning goals of the organisation), and 'improvement judgement' (assesses how the planning system has evolved or adapted over time in supporting organisational planning needs). Also, they identified four main dimensions of ITSP success:

a alignment of the IS strategy and business strategy

b analysis to provide a clear understanding of how information is used within the organisation and uncover critical development areas

c cooperation to reduce potential conflict which may jeopardise the implementation of strategic IS plans

d improvement in capabilities of the planning process to adapt to changing circumstances.

\subsection{Importance of organisational factors}

There currently exist numerous frameworks proposed for ISP which are summarised by Wang and Tai (2003), and Lee and Bai (2003). Despite the growing number of IT strategic planning frameworks proposed, organisations still fail to successfully implement ITS. The main reason for this failure is the greater emphasis on technical and technological aspects of IT while neglecting organisational (e.g., non-technical) factors (Lee and Bai, 2003; Mentzas, 1997; Lee and Gough, 1993).

Hackney and Little (1999), and Reponen (1993) also mentioned in their studies that IT/ISSP should be considered from an organisational perspective. Therefore, the effectiveness of ISP processes depends on organisational characteristics (Premkumar and King, 1994).

Because of the importance of organisational factors in employing a successful IT/ISSP strategy, we developed and tested a general model to illustrate in this article various organisational factors which influence the effectiveness and success of IT/ISSP. 


\subsection{Present study's approach and contribution}

Most of the previous researches have studied factors affecting the success of either 'ITSP process' or 'alignment between IT and business (strategic alignment)'. In this research, inspired from previous researches, we have investigated factors affecting the success of both of these major concepts together as well as their effects on each other. We have also studied organisational factors by categorising them in to two-groups in terms of cooperation between major elements and actors of ITSP projects, for the purpose of:

a to emphasise the importance of cooperation and its influence on strategic alignment and effectiveness of ITSP

b to show the influence of cooperative factors on ITSP effectiveness indirectly through affecting strategic alignment.

\section{Components of conceptual model and hypotheses development}

\subsection{Conceptual framework}

The preliminary research questions were: What are the organisational critical success factors (CSFs) affecting the success of IT/ISSP? What sort of causal relationship is there between organisational factors and effectiveness of IT/ISSP? What are the main factors affecting alignment between business and IT strategy? What are the influences of Business-IT alignment on IT/ISSP success?

This paper asserts that organisational factors can affect the success of IT/ISSP both indirectly, through the mediating effects of the strategic alignment - as a part of the IS/IT strategic planning dimensions-, and directly, by influencing the quality of IT/ISSP. Inspired by building blocks of Wang and Tai's (2003) conceptual framework, ours (Figure 1) consists of three domains:

a organisational factors (Bai and Lee, 2003; Lee and Bai, 2003; Basu et al., 2002; Segars and Grover, 1998)

b IT/ISSP dimensions which includes strategic alignment (Segars and Grover, 1998) and environmental assessment (Wang and Tai, 2003)

c IT/ISSP effectiveness (Basu et al., 2002; Segars and Grover, 1998).

Accordingly, in our model, factors affecting the success of the IT/ISSP process consist of both organisational factors and IS/IT strategic planning dimensions.

In this study, we intend to go over organisational factors from 'cooperation' perspective in order to differentiate factor affecting IT/ISSP effectiveness and the ones affecting strategic alignment. We have therefore categorised these factors in to two groups:

a cooperative organisational factors which contain interactional factors strongly needed communications between actors having significant effects on strategic alignment

b non-cooperative organisational factors which represent infrastructural and administrative factors having significant effects on effectiveness of IT/ISSP. 
On the other hand, since IT/ISSP should be articulated in terms of an external and internal domain (Henderson and Venkatraman, 1993), we have therefore studied IT/ISSP in terms of its internal and external dimensions. In a way that strategic alignment covers the internal dimension and environmental assessment covers the external dimension.

Figure 1 Research conceptual framework (see online version for colours)

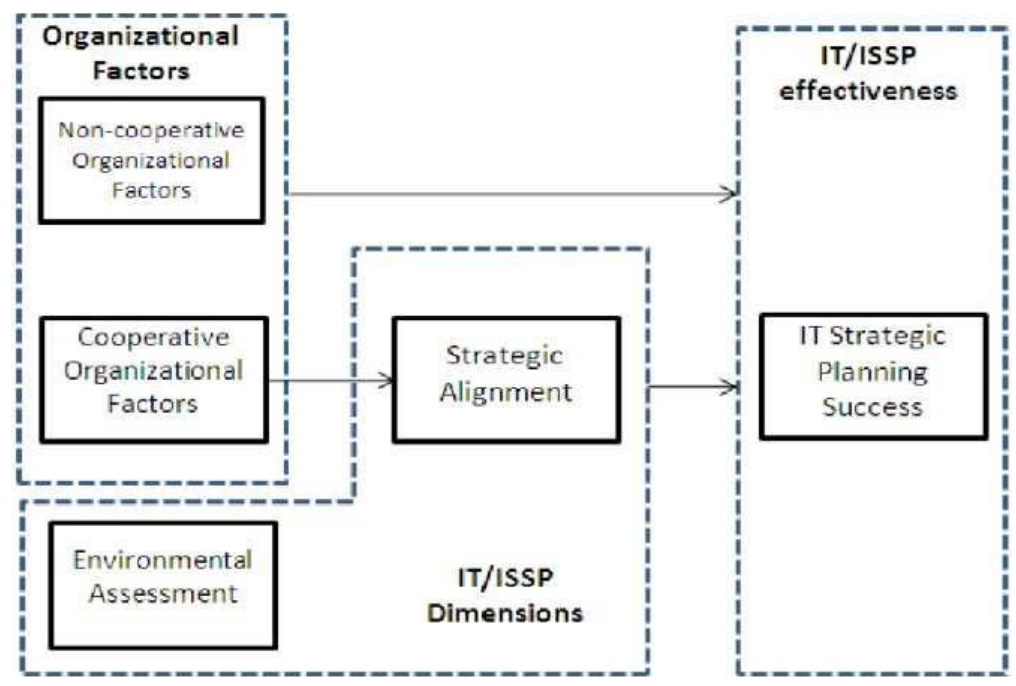

\subsection{Hypotheses development}

The hypotheses are summarised in the research model depicted in Figure 2.

Figure 2 Related variables to every hypotheses

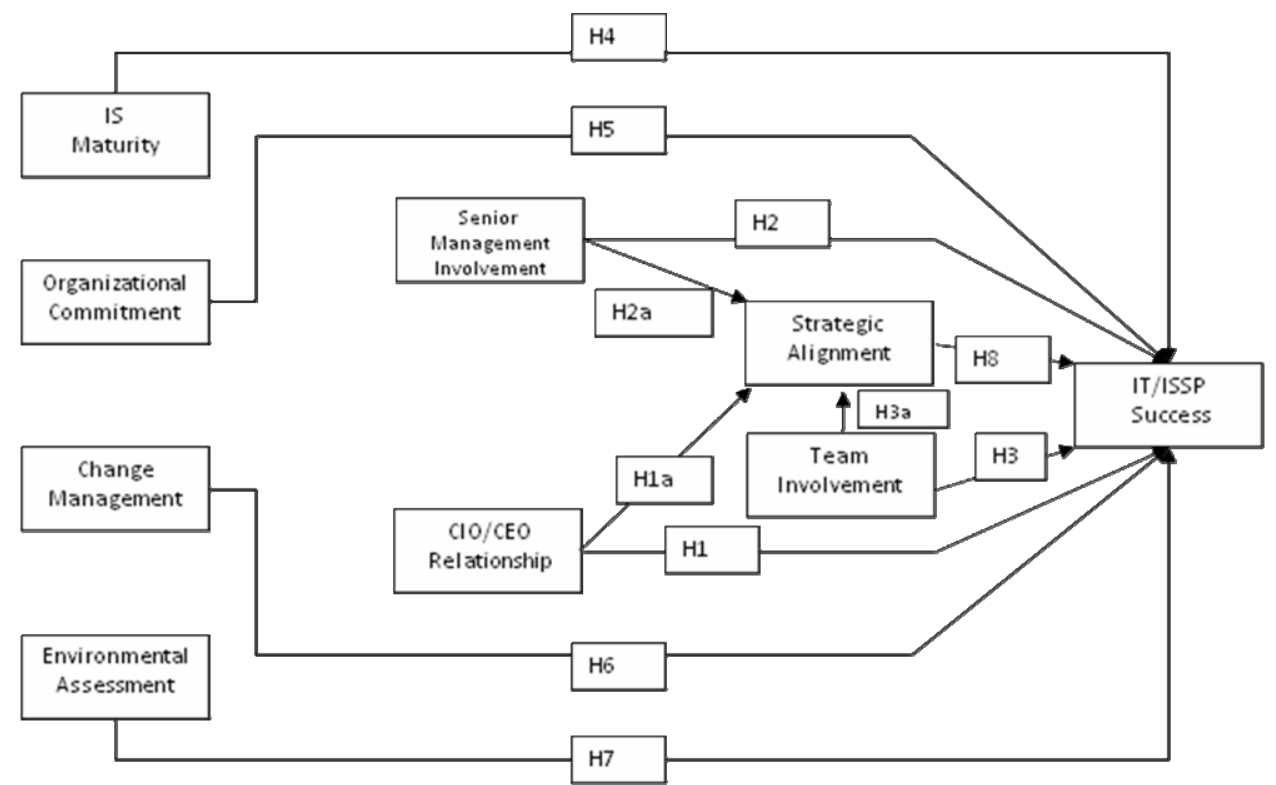




\subsubsection{Cooperative organisational factors}

\section{CIO and CEO relationship}

This relation concerns the CEOs contribution on considering the components of business strategy in IT plan as well as CIOs contribution on developing IT-enabled business strategies (Tai and Phelps, 2000; Feeny et al., 1992). If the relationship between CEOs and CIOs is poor, it affects the quality of the IT/ISSP also prevents placing a high value on IS (Bai and Lee, 2003; Cerpa and Verner, 1998).

Feeny et al. (1992) investigated CIO/CEO relationship by considering some CIO, CEO and organisational attributes in an excellent relationship between CIO and CEO. They argued that good CIO/CEO relationship will attribute to success in at least three aspects: SISP, business/IS partnership and, CEO involvement in IT management. Moreover, closer relationship leads to have a better understanding of CEOs expectations of IT (Cerpa and Verner, 1998).

Also, the practitioner literature suggests that effective ClOs must skilfully apply their powers of influence to encourage other functional heads to become partners with them and embrace ownership of these initiatives (Enns et al., 2003).

Tai and Phelps (2000) proposed a model incorporating the dimensions of IT/ISSP impacted by relationship between CIO and CEO. They reported that good relationship leads to improve the similarity of IT perceptions, impact all dimensions of ITSP and give a strong effect for IT issues.

Sherer (2004) has considered the importance of this relationship on IT governance as the major result of a good ITSP process. This relationship could manage under an IT steering committee and accordingly strategic criteria are used more often when justifying IT investments. Additionally, Niederman et al. (1991) made a theoretical contribution by classifying key issues in IS management in various dimensions, such as management versus technology issues. In their classifications, the correlation between a positive relationship (between $\mathrm{CIO}$ and CEO) and the success of the program is clear.

H1 CIO and CEO relationship is positively-related to IT strategic planning success (effectiveness).

H1a CIO and CEO relationship is positively-related to strategic alignment.

\section{Senior management involvement}

Senior management involvement in IT/ISSP means that top executives champion this project (Basu et al., 2002), which shows their commitment as well as the importance of the project. IT/IS-related projects often take more time and cost much more than originally expected. While the problem of cost overruns has traditionally been attributed to the poor quality of the original estimates, it has recently been recognised the senior management involvement and commitment as an additional reason (Newman and Sabherwal, 1996).

Basu et al. (2002) in their research have illustrated the critical role of senior management involvement in IT strategic planning success. Also, Earl (1993) reported senior management involvement as the highest ranked CSF for IT/ISSP projects.

Newman and Sabherwal (1996) showed sustained involvement and commitment (in executive management level) to be a key requirement for successfully completing 
any IS projects. Jarvenpaa and Ives (1991) used 'executive participation' term for senior management involvement. Executive participation is concerned with CEO behaviours-related to ISP, development and implementation. This kind of involvement is also concerned with the psychological state of the CEO reflecting the degree of importance placed on the ITSP project by senior manager.

In our study, we have taken into consideration the amount of senior management involvement. Cerpa and Verner (1998) mentioned that ISSP is a job for IS planning staff and though senior management involvement is needed, much involvement is not. To be involved, senior management does not need to take a 'hand-on' role that is to spend his or her personal time. Rather, the involved senior manager only needs to view IT as contribution to the firm's success (Jarvenpaa and Ives, 1991). Therefore, the degree of senior management involvement is important.

H2 Senior management involvement is positively-related to IT strategic planning success (effectiveness).

H2a Senior management involvement is positively-related to strategic alignment.

\section{Team involvement}

Team involvement in IT/ISSP refers to soliciting of IT planning inputs from different organisational levels which are responsible for plan implementation (Basu et al., 2002). A IS/IT strategic planning team which consists of business managers, IS managers, user managers and unit managers can help the organisation to achieve consensus through effective communication and interaction and achieve their IS decision-making goals (Pai, 2006).

Basu et al. (2002) in their research have illustrated the role of team involvement in IT strategic planning success. In team involvement, some key points are: keeping the planning team aware of business changes and selection of ISSP team members on the basis of competence and their high credibility. Furthermore, training ISSP team about ISSP methodologies, ISSP scope and goals and also organisation's mission and purpose and its environment are crucial in team involvement (Basu et al., 2002).

H3 Team involvement is positively-related to IT strategic planning success (effectiveness).

H3a Team involvement is positively-related to strategic alignment.

\subsubsection{Non-cooperative organisational factors}

\section{IS maturity}

IS maturity considers the level of technical and managerial IT infrastructure within the organisation which concerns number of IT-enabled functions, IT penetration, technical infrastructure (mainframes, process control devices, micros, etc.), IS performance evaluation, IS managers' knowledge about the firm's business plans and vice versa as well as IS planning formalisation (Sabherwal and King, 1995).

In a case study conducted by Cerpa and Verner (1998), they described the changes and developments that have taken place over a period of four-years and considered the strategic relevance of ISSP to the firm and the growth in IS maturity. They pointed out 
some key issues in this regard: involvement and commitment of senior management, linking IS to business goals, choosing the right ISSP methodology, availability of right skills and expertise and ongoing evaluation of ISSP. Sabherwal and King (1995) considered IS maturity as a major attribute of decision-making process concerning strategic applications of IS. They showed that the maturity of IS functions are critical in the identification of strategic IS. Accordingly, mature IS functions, facilitate greater IS influence and more long-term approach during the strategic decision process.

H4 IS maturity is positively-related to IT strategic planning success (effectiveness).

\section{Organisational commitment}

It means company support for IT/ISSP and consists of presence of sufficient resources for it, conflict management to resolve potential conflicts between organisational subunits, and reasonable management's expectations for the result of ISSP (Basu et al., 2002). Organisational commitment considers commitment of highly credible persons in order to show the importance of the project in operational level of the organisation - as the main stakeholder of the IT/ISSP project.

Gottschalk (1999) investigated the effect of:

a description of responsibility for ISSP process

b description of user involvement on ISSP process.

This study showed the greater the extent of these two variables of organisational commitment, the greater the extent of ISSP success.

H5 Organisational commitment is positively-related to IT strategic planning success (effectiveness).

\section{Change management}

Organisational change is an important method for facilitating the change and development of organisational structure, culture, tasks, personnel and working skills. Numerous internal and external factors can cause organisational change; some of which are uncontrollable and classified as non-planned changes, while others are classified as planned changes (Lee and Bai, 2003). Introducing IT and IS into an organisation requires organisational change and signifies that functions must be put in place to reduce resistance to this change; both structural issues that have an important effect on the development of the organisation.

IT/ISSP affects all the organisational layers and requires changing in the current business and IT architecture in order to migrate to the optimal situation. Thus, change management should be considered as the vital part of IT/ISSP process (Lee and Bai, 2003).

Change management should address change in the organisational culture, workflow patterns, relationship patterns, changes resulting from business process reengineering, etc. (Haki and Manian, 2005).

H6 Change management is positively-related to IT strategic planning success (effectiveness). 


\subsubsection{IT strategic planning dimensions}

\section{Environmental assessment}

Environmental assessment comprises of the organisation's assessments of its internal (strengths, weaknesses, past performance, reasons for past failures and, feasibility of the intended plan) and external (trends in economics, policy, society, regulations and technology) environment (Wang and Tai, 2003).

Wang and Tai (2003) argued that with comprehensive assessment of internal and external environments, an organisation can identify tools, methodologies and mechanisms useful for developing effective IT plans, thereby making it more adaptive. It is then natural to expect that the extent of environmental assessment will positively affect the capability of IT planning.

H7 Environmental assessment is positively-related to IT strategic planning success (effectiveness).

\section{Strategic alignment}

A key aspect of IT planning is the alignment of IT plans with business plans through coordination between business and IT planning functions and activities. This alignment is necessary to ensure that the IS functions support organisational goals and activities at every level in order to achieve business value from IT and exploit IT to strategic advantage (Teo and Ang, 1999).

Kearns and Lederer (2000) investigated a two-way relationship between IS plan and business plan from the perspective of IS executives and business executives. Findings from this study strongly support the expectation that alignment of IS with business plan produces the use of IS-based resources for competitive advantage, in both IS and business executives' point of view.

Henderson and Venkatraman (1993) argue that the inability to realise value from IT investment is due to the lack of alignment between the business and IT strategies of organisations. Investments in IT are often decided on the basis of the IS plan (Kearns and Lederer, 2000). Therefore, this alignment affects the effectiveness of IT planning (Raghunathan and Raghunathan, 1994).

H8 Strategic alignment is positively-related to IT strategic planning success (effectiveness).

\section{Research methodology}

\subsection{Data collection and sample characteristics}

At the time of conducting the survey in Iran, the number of organisations which developed IT/ISSP was very limited. As planner satisfaction is a main measure for assessing the success of IT/ISSP (Lederer and Sethi, 1996). Therefore:

a the sample adopted was the IT strategic planning (or IT master plan and enterprise architecture) project managers, project members and consultants in the top ranked ICT consultancy companies published by informatics society of Iran and Iranian high council of informatics 
b also, questionnaires were distributed between ICT experts in top ranked universities and ICT research centres throughout the country.

It led to access to enough qualified respondents.

Questionnaires were distributed physically (on site) and electronically (via dedicated webpage). A cover letter explained the objectives of the study.

Out of 218 questionnaires distributed, 99 completed questionnaires were returned. Of those, 94 questionnaires were usable, indicating a $45 \%$ rate of return.

The respondents were all IT strategic planning experts with an average of 7 years' work experience with $61 \%$ holding a Master of Science degree in the field of IT.

\subsection{Independent and dependent variables}

Multi-item scales were employed for measuring the research variables, using five-point Likert-type scales ranging from (5) strongly agree to (1) strongly disagree (see the Appendix).

In this research, variables are classified into three groups. Groups comprising the main components of an information technology strategy (ITS) success model are: organisational factors (cooperative and non-cooperative organisational factors), IT strategic planning dimensions and IT strategic planning effectiveness.

Non-cooperative organisational factors evaluated include IS maturity, organisational commitment and change management. Cooperative organisational factors consist of CIO and CEO relationship, senior management involvement and team involvement. IT strategic planning dimensions consist of strategic alignment and environmental assessment (both internal and external environmental assessment).

Accordingly, we have identified independent variables as: change management, organisational commitment, IS maturity, senior management involvement, team involvement, CIO and CEO relationship and environmental assessment while dependent variables are strategic alignment and IT strategic planning success (effectiveness).

\subsection{Pre-testing}

The pre-testing process focused on clarity, wording and validity of questions. The questionnaire was revised during two phases of pre-testing: phase 1, the questionnaire was modified by three $\mathrm{PhD}$ students and two IT strategic planning experts with at least 10 years' work experience in related fields. The questionnaire was again modified in phase 2 by three IT strategic planning project managers with at least 15 years' work experience in related fields.

\section{Data analysis and results}

\subsection{Reliability of variables}

Cronbach's alpha was used to determine an unbiased estimate of measurement reliability; it indicates the degree of internal consistency among the measurement items and is inversely-related to the degree to which a measure is contaminated by random error. 
As shown in Table 1, Cronbach's alpha for every construct is greater than 0.7 and for all items are 0.98 . The constructs are therefore considered to exhibit adequate reliability.

Table 1 Reliability coefficient of research variables

\begin{tabular}{|c|c|c|c|}
\hline Variables & & Number of questions & Cronbach's alpha \\
\hline \multirow{7}{*}{$\begin{array}{l}\text { Independent } \\
\text { variables }\end{array}$} & Change management & 4 & 0.86 \\
\hline & Organisational commitment & 4 & 0.86 \\
\hline & Information systems maturity & 5 & 0.91 \\
\hline & Senior management involvement & 5 & 0.87 \\
\hline & Team involvement & 4 & 0.87 \\
\hline & CIO and CEO relationship & 4 & 0.85 \\
\hline & Environmental assessment & 8 & 0.92 \\
\hline \multirow{2}{*}{$\begin{array}{l}\text { Dependent } \\
\text { variables }\end{array}$} & Strategic alignment & 5 & 0.85 \\
\hline & IT strategic planning success & 6 & 0.93 \\
\hline
\end{tabular}

\subsection{Content validity of variables}

The content validity of the questionnaire was established through two actions: first, the variables and measurement items extracted from the adopted variables and the items that have been used and validated by previous research. The Appendix lists the measurement items of each research variable and its references. Secondly, the questionnaire was revised through the two-step process of pre-testing as previously mentioned.

\subsection{Construct validity of variables}

Confirmatory factor analysis (CFA) was used to examine the construct validity and assess the underlying factor structures of the measurement items. We used LISREL 8.5 software for CFA and path analysis. Linear structural relations (LISREL), is a statistical software package used in structural equation modelling (SEM).

When the total number of measurement items is large, they can be divided into select heterogeneous groups for factor analysis (Kaiser, 1958). Accordingly, we classified nine variables and 45 items into three groups:

a organisational factors (non-cooperative organisational factors, cooperative organisational factors)

b IT strategic planning dimensions

c IT strategic planning effectiveness.

The Appendix illustrates each group and their related variables and items along with the item's acronym used in LISREL software analysis.

One can also conduct CFA by dividing a wide range of variables into two groups of $\mathrm{X}$-model (independent variables) and Y-model (dependent variables). We used both afore-mentioned methods for CFA. For the purposes of this paper, we have shown only CFA by X-model and Y-model analysis. 
Figure 3 Measurement models for independent and dependent variables (see online version for colours)

X-model

उMGT 1

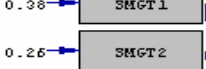

$0.40 \rightarrow$ इसGT 3

SMGT 4

SerGT 5

$0.33 \rightarrow$ ORCM1

$0.30 \rightarrow 0$ ORCH2

$0.29 \rightarrow$ oRchs

$0.32 \rightarrow$ ORCer 4

$0.28 \rightarrow$ TE AMI

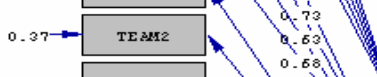

$0.28 \rightarrow$ TE343

CHMG1

$0.13 \rightarrow$ CHMG

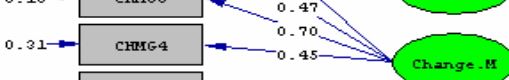

CICE1

cICE 4 cics 3

$0.18 \rightarrow$ ISMAL 0.01

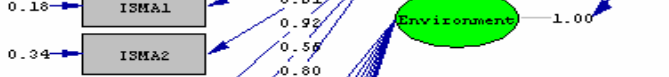

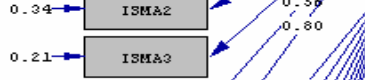

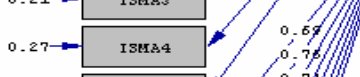

$0.22 \rightarrow$ ISMas

$0.21 \rightarrow$ IMEA1

$0.40 \rightarrow$ IMEA2 $/ 20$

$0.38 \rightarrow$ IMEA3 $/$

$0.22 \rightarrow$ EXEA1

EXEA2

$0.25 \rightarrow \operatorname{EXEA3}$

$0.28 \rightarrow 0 \times 245$

$0.46 \rightarrow$ EXEAS

Notes: Senior $=$ senior management involvement; Org.comm = organisational commitment; Team.I = team involvement; Change. $\mathrm{M}$ = change management; $\mathrm{CEOCIO}=\mathrm{CEO} / \mathrm{CIO}$ relationship; Environ = environment assessment; ISPS $=$ IT/ISSP success

Y-model

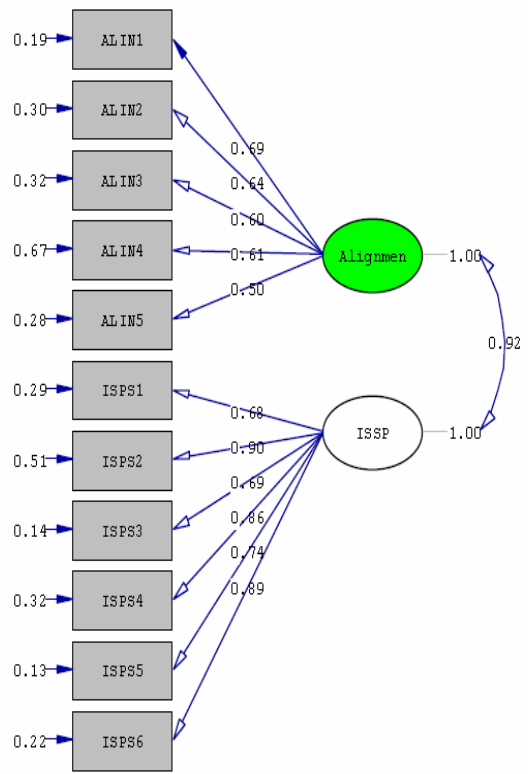




\subsubsection{CFA for independent ( $X$-model) and dependent ( $Y$-model) variables}

Figure 3 illustrates the measurement models for independent and dependant variables. After developing $\mathrm{X}$ - and Y-model, we modified output models based on suggested modifications by LISREL. It leads to more reliable representation of study's results. Table 2 compares the goodness of fit indexes for the first and modified measurement models.

Modified measurement models in both $\mathrm{X}$-model and $\mathrm{Y}$-model have lower Chi-square, SRMR index is close to zero and other goodness of fit indexes are close to 1 .

Table 2 Comparison the goodness of fit indexes for first and modified measurement model for independent and dependent variables

\begin{tabular}{|c|c|c|c|c|c|c|c|c|}
\hline & & Chi-square & $G F I$ & $A G F I$ & CFI & $N F I$ & $N N F I$ & SRMR \\
\hline \multirow{2}{*}{$\begin{array}{l}\text { Independent } \\
\text { variables }\end{array}$} & First model & 1527.82 & 0.78 & 0.70 & 0.94 & 0.91 & 0.93 & 0.082 \\
\hline & $\begin{array}{l}\text { Modified } \\
\text { model }\end{array}$ & 292.76 & 0.92 & 0.89 & 0.97 & 0.95 & 0.96 & 0.054 \\
\hline \multirow{2}{*}{$\begin{array}{l}\text { Dependent } \\
\text { variables }\end{array}$} & First model & 196.39 & 0.83 & 0.78 & 0.91 & 0.89 & 0.89 & 0.076 \\
\hline & $\begin{array}{l}\text { Modified } \\
\text { model }\end{array}$ & 92.49 & 0.92 & 0.89 & 0.93 & 0.91 & 0.91 & 0.055 \\
\hline
\end{tabular}

\subsection{Research structural equation model}

The SEM approach was applied to test the proposed model. We used the modified measurement models to develop the structural equation model of this research. SEM is a statistical technique for testing and estimating causal relationships using a combination of statistical data and qualitative causal assumptions. Figure 4 shows the structural equation model between dependent and independent variables.

Goodness of fit indexes for the structural equation model indicates a very good fit (Chi-square $=1123.24, \mathrm{GFI}=0.91, \mathrm{AGFI}=0.89, \mathrm{NFI}=0.93, \mathrm{CFI}=0.95, \mathrm{NNFI}=0.94$, IFI $=0.95, \mathrm{RMR}=0.059$, SRMR $=0.070$ ).

Hence, the structural equation model is acceptable for determining the causal relations between variables and testing hypotheses of this study.

Table 3 shows path coefficient and t-value of every structural relation in the structural equation model.

Table 3 Result of structural equation model

\begin{tabular}{llccc}
\hline \multicolumn{2}{l}{ Independent variables } & Dependent variables & Path coefficient & t-value \\
\hline $\begin{array}{l}\text { Organisational } \\
\text { factors }\end{array}$ & $\begin{array}{l}\text { Cooperative } \\
\text { organisational factors }\end{array}$ & ITSP success & -0.083 & -0.32 \\
& $\begin{array}{l}\text { Non-cooperative } \\
\text { organisational factors }\end{array}$ & ITSP success & 0.92 & 9.16 \\
$\begin{array}{l}\text { IT strategic } \\
\text { planning } \\
\text { dimensions }\end{array}$ & $\begin{array}{l}\text { Environmental } \\
\text { assessment }\end{array}$ & ITSP success & 0.44 & 2.44 \\
\hline
\end{tabular}


Calculated t-value indicates that there is a causal relation between non-cooperative organisational factors (path coefficient $=0.44$ ), environmental assessment (path coefficient $=0.47$ ) and strategic alignment (path coefficient $=0.28$ ) with IT strategic planning success. Also, there is a strong causal relation between cooperative organisational factors and strategic alignment (path coefficient $=0.92$ ). But there is no causal relation between cooperative organisational factors and IT strategic planning success (path coefficient $=-0.083$ ). In other words, cooperative organisational factors influence IT strategic planning success indirectly through their effects on strategic alignment.

Figure 4 Structural equation model (see online version for colours)

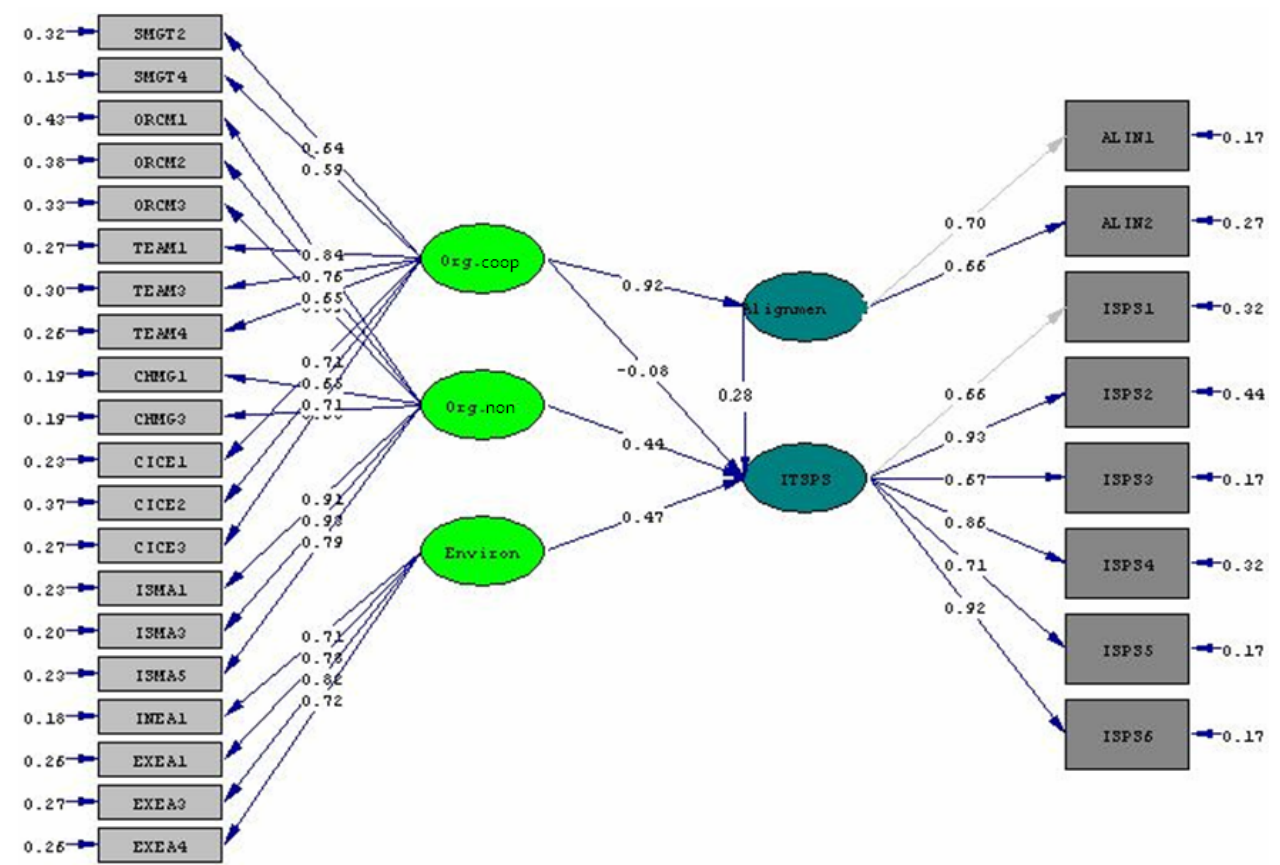

Notes: Org.coop = cooperative organisational factors; Org.non = non-cooperative organisational factors.

\subsection{Hypotheses testing}

We used the path analysis method for hypotheses testing. Path analysis is a type of multiple regression analysis which can be viewed as a special case of SEM - one in which only single indicators are employed for each of the variables in the causal model.

Figure 5 shows the path diagram for testing the research hypotheses. This diagram consists of relations between all research variables which is an output of LISREL software. 
Figure 5 Research path diagram (see online version for colours)

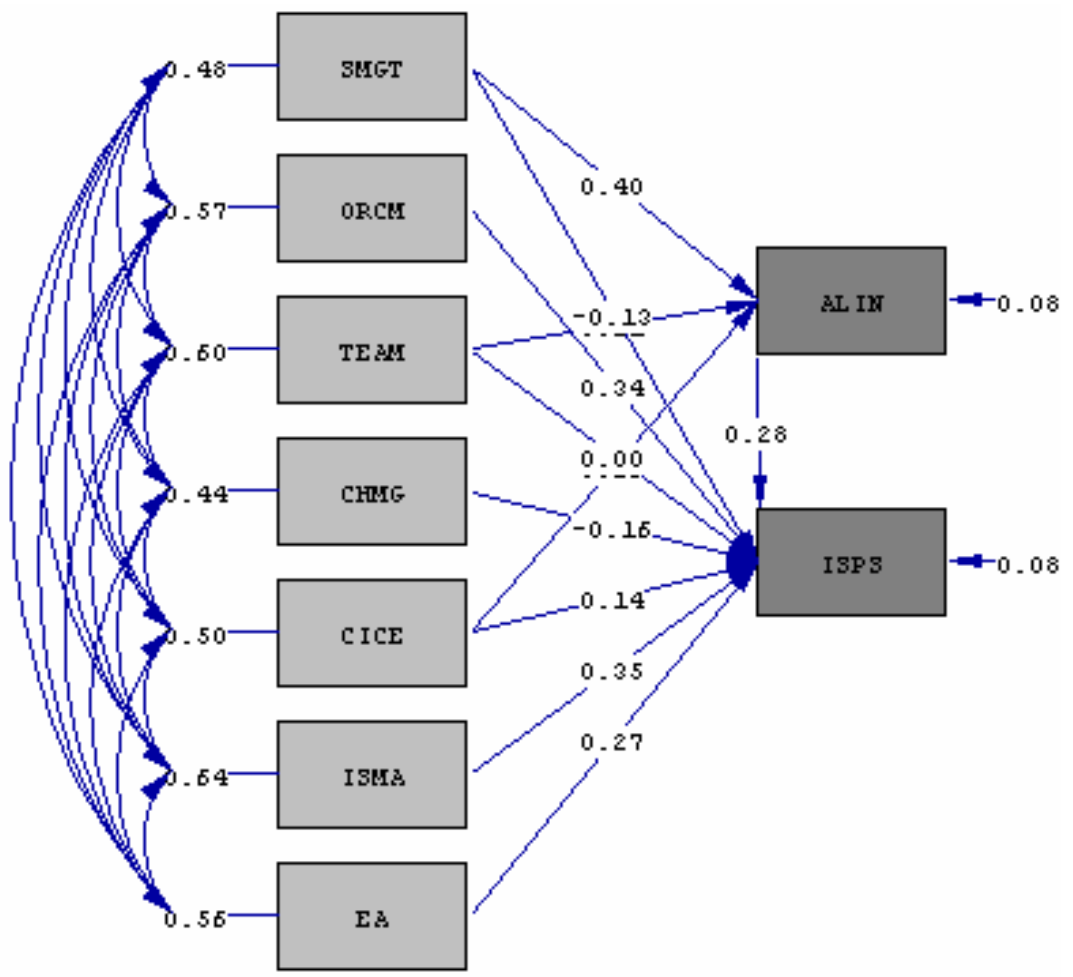

Table 4 Acceptability status of each research hypotheses

\begin{tabular}{lccccc}
\hline $\begin{array}{l}\text { Independent } \\
\text { variables }\end{array}$ & Dependent variables & $\begin{array}{c}\text { Path } \\
\text { coefficient }\end{array}$ & t-value & Hypotheses & Acceptability \\
\hline $\begin{array}{l}\text { Senior management } \\
\text { involvement }\end{array}$ & ITSP success & -0.13 & -1.29 & $\mathrm{H} 2$ & $\mathrm{~N}$ \\
Team involvement & Strategic alignment & 0.40 & 5.21 & $\mathrm{H} 2 \mathrm{a}$ & $\mathrm{Y}$ \\
& ITSP success & 0.0033 & 0.029 & $\mathrm{H} 3$ & $\mathrm{~N}$ \\
CIO and CEO & ITSP success & 0.14 & 1.37 & $\mathrm{H} 1$ & $\mathrm{Y}$ \\
$\begin{array}{l}\text { relationship } \\
\text { Organisational }\end{array}$ & Strategic alignment & 0.29 & 3.28 & $\mathrm{H} 1 \mathrm{a}$ & $\mathrm{Y}$ \\
$\begin{array}{l}\text { commitment } \\
\text { Change }\end{array}$ & ITSP success & 0.34 & 4.58 & $\mathrm{H} 5$ & $\mathrm{Y}$ \\
$\begin{array}{l}\text { management } \\
\begin{array}{l}\text { Information } \\
\text { systems maturity }\end{array}\end{array}$ & ITSP success & -0.16 & -1.81 & $\mathrm{H} 6$ & $\mathrm{~N}$ \\
$\begin{array}{l}\text { Environmental } \\
\text { assessment }\end{array}$ & ITSP success & 0.35 & 3.24 & $\mathrm{H} 4$ & $\mathrm{Y}$ \\
$\begin{array}{l}\text { Strategic alignment } \\
\text { ITSP success }\end{array}$ & ITSP success & 0.27 & 2.83 & $\mathrm{H} 7$ & $\mathrm{Y}$ \\
\hline
\end{tabular}


Goodness of fit indexes for research path diagram indicates a very good fit (Chi-square $=14.31$, GFI $=0.97, \mathrm{CFI}=0.99, \mathrm{NFI}=0.99, \mathrm{NNFI}=0.95, \mathrm{IFI}=0.99$, $\mathrm{RMR}=0.0061, \mathrm{SRMR}=0.013)$. Hence, this path diagram is acceptable for testing the research hypotheses.

Table 4 shows the acceptability status of each research hypotheses based on path coefficient and t-value.

\section{Discussion and conclusions}

This paper asserts that organisational factors can affect the success of IT/ISSP indirectly through the mediating effects of the IS/IT strategic planning dimensions, while these dimensions can influence the quality of IT/ISSP directly.

CFA was used to examine the construct validity and path analysis was used for testing research hypotheses. We utilised LISREL 8.5 software for data analysis.

We developed modified measurement models for dependent and independent variables based on suggested modifications by LISREL. These models were then modified for developing the structural equation model. Based on our valid equation model, we found a causal relation between non-cooperative organisational factors, environmental assessment and strategic alignment and IT strategic planning success. Additionally, a strong causal relation exists between cooperative organisational factors and strategic alignment. Conversely, there exists no causal relation between cooperative organisational factors and IT strategic planning success. In other words, cooperative organisational factors influence IT strategic planning success indirectly through the effect on strategic alignment.

We then developed a research path diagram for testing our research hypotheses. Based on our valid path diagram, IT strategic planning effectiveness is a function of strategic alignment, organisational commitment, environmental assessment, IS maturity and the CIO/CEO relationship. Furthermore, strategic alignment is a function of senior management involvement, team involvement and the CIO/CEO relationship.

\subsection{Limitations}

Since this research has been done in Iran, the most significant limitation of the present study was limited accessibility to qualified respondents for the questionnaire, as at the time of conducting this research, IT strategic planning was a novel issue in Iranian IT market.

Due to the above mentioned fact, the major limitations of our study were as follows: First, we expanded the sample of our research to all the ITSP project managers, project members, consultants and ICT experts. Hence, the sampling method of this research was that of convenience. Also, generalising the findings of this research to organisations of other countries may not be practical.

Second, according to the limitations of sampling process, sample size was also a significant limiting aspect of our research. It was mainly due to using SEM and CFA in our data analysis phase. In this process we could only have 94 usable questionnaires after spending considerable time for data collection. To achieving more reliable results, a bigger sample size was required. 
Third, we have not been able to use all measurement items of reference researches due to the lack of respondent's sense of questions to some of those items. Hence, we had a selective approach to using other researches' items.

Therefore there is no claim that this research has captured all aspects of study variables and detailed requirements of data analysis process. Nevertheless for the sake of reliability, all the measurement items have been adapted from previous researches and the questionnaire was revised through the two-step process of pretesting in order to localise the terminology of the research concept.

\subsection{Implications for future research}

We considered the effects of cooperative organisational factors based on the resulting effects upon strategic alignment. In our study, we did not find that these factors had a significant direct effect on ITSP success. Therefore future studies could look further into uncovering other direct factors of ITSP success. However, in order to evaluate the vital role that strategic alignment plays in ITSP projects, further study into a complete list of cooperative organisational factors on strategic alignment would be useful.

Of our results, the discovery that change management had no effect on ITSP success is even more compelling. Perhaps change management activities in our sample were not sufficiently effective for reducing resistance to change. Further research could attempt to explain this finding.

Apart from factors influencing the effectiveness and success of ITSP, future researches may focus on ITSP project itself. According to the importance of ITSP projects, finding CSFs or critical failure factors as well as developing a 'reference project framework' should be useful. To develop a reference framework, using component-based approach is advisable. Since the final deliverable of this kind of projects is a document, a major concern is updating this document based on business or technology changes. The question is that what framework with which specifications could effectively support this updating process. The research should identify the major activities of the project, their relationship as well as classifying these activities within manageable components. Due to the challenges of using SEM method in this study and other researches, consideration of advantages and disadvantages of using SEM method in IS researches will be valuable. Moreover, if applicable, special considerations for using this method in IS researches may also be recommended.

\subsection{Implications for practice}

An ITSP project is not only necessary for goal-based development of IT applications, but also brings with it greater flexibility and agility in an organisation's business processes; ultimately basing the processes on business needs and carrying state-of-the-art IT features.

Based on our results, strategic alignment is at the core of every IT strategic planning project. In order to achieve a better alignment between business and IT strategies, teamwork between IT and business managers is crucial. ITSP is a multidisciplinary project and its success requires using business and IT experts' expertise at the same time. A good business model only could run on a bug-free data and technical model and viceversa; a state-of-the art IT infrastructure could have value-added by connecting to a well- 
defined business process map. Hence, lack of participation from either business or IT part of the project leads to failure.

Furthermore, the amount of top management support surrounding the ITSP project determines the success and failure of these kinds of projects. According to the result of data analysis, our hypotheses for relation between 'senior management involvement' and strategic alignment approved but its relation with ITSP success failed. There is a practical fact behind this result. Senior management could have a mediator role for aligning business and IT strategies also creating a general commitment throughout the company for ITSP project which leads to speed up the project. Senior manager could be a best project champion. On the other way around, senior management's involvement should have a limitation otherwise all the project's activities would be affected by his (her) authority and may be deviated from pre-determined objectives. On the other words, not enough or too much senior management involvement is a major reason of ITSP projects' failure.

Success of ITSP projects highly related to achieve a general commitment of managers and organisation's key members to the project. The project manager have to arrange some general meetings, e.g., kick off meeting and some meetings for presenting project's deliverables-and invite all the organisation's managers and key members and present the project progress, requirements and explain the required and potential role of organisation's members in each phase of the project.

Apart from organisation's members, project manager have to be able to harmonise different field of experiences in such a multidisciplinary project. Since team members have different expertise and different level of experiences, hence, project manager is supposed to effectively manage their involvement in team activities. It could be more manageable by having two vice managers for handling 'business' and 'IT' part of the project.

\section{References}

Bai, R.J. and Lee, G.G. (2003) 'Organizational factors influencing the quality of the IS/IT strategic planning process', Industrial Management and Data Systems, Vol. 103, No. 8, pp.622-632.

Baker, B. (1995) 'The role of feedback in assessing information systems strategic planning effectiveness', Journal of Strategic Information Systems, Vol. 4, No. 1, pp.61-80.

Basu, V., Hartono, E., Lederer, A.L. and Sethi, V. (2002) 'The impact of organizational commitment, senior management involvement and team involvement on strategic information systems planning', Information and Management, Vol. 39, pp.513-524.

Battaglia, G. (1991) 'Strategic information planning: a corporate necessity', Journal of Systems Management, February, pp.23-26.

Brancheau, J.C., Janz, B.D. and Wetherbe, J.C. (1996) 'Key issues in information systems management: 1994-1995 SIM Delphi results’, MIS Quarterly, Vol. 20, No. 2, pp.225-242.

Cerpa, N. and Verner, J.N. (1998) 'Case study: the effect of IS maturity on information systems strategic planning', Information \& Management, Vol. 34, No. 4, pp.199-208.

Earl, M.J. (1993) 'Experiences in strategic information systems planning', MIS Quarterly, March, Vol. 22, pp.1-24.

Enns, H.G., Huff, S.L. and Higgins, C.A. (2003) 'CIO lateral influence behaviour: gaining peer's commitment to strategic information systems', MIS Quarterly, Vol. 16, No. 4, pp.435-448.

Feeny, D.F., Edwards, B.R. and Simpson, K.M. (1992) 'Understanding the CEO/CIO relationship', MIS Quarterly, Vol. 27, No. 2, pp.155-176. 
Gottschalk, P. (1999) 'Strategic information systems planning: the IT strategy implementation matrix', European Journal of Information Systems, Vol. 8, No. 2, pp.107-118.

Gottschalk, P. (2001) 'Key issues in IS management in Norway: an empirical study based on Q-methodology', Information Resources Management Journal, Vol. 14, No. 2, pp.37-45.

Hackney, R. and Little, S. (1999) 'Opportunistic strategy formulation for IS/IT planning', European Journal of Information Systems, Vol. 8, pp.119-126.

Haki, M.K. and Manian, A. (2005) 'Factors affecting the success of information technology/information systems strategic planning: with organizational approach', International Conference on Information and Communication Technology in Management, pp.744-757, Melaka, Malaysia.

Henderson, J.C. and Venkatraman, N. (1993) 'Strategic alignment: leveraging information technology for transforming organizations', IBM Systems Journal, Vol. 38, No. 283, pp.472-484.

Ho, F.C. (1996) 'Information technology implementation strategies for manufacturing organizations - a strategic alignment approach', International Journal of Operations \& Production Management, Vol. 19, No. 7, pp.77-100.

Jarvenpaa, S.L. and Ives, B. (1991) 'Executive involvement and participation in the management of information technology’, MIS Quarterly, June, pp.205-227.

Kaiser, H. (1958) 'The varimax criterion for analytic rotation of factors', Psychometrika, Vol. 23, pp.187-200.

Kearns, G.S. and Lederer, A.L. (2000) 'The effect of strategic alignment on the use of IS based resources for competitive advantage', Journal of Strategic Information Systems, Vol. 9, pp.265-293.

Lederer, A.L. and Sethi, V. (1996) 'Key prescriptions for strategic information systems planning', Journal of Strategic Information Systems, Vol. 13, No. 1, pp.35-62.

Lee, G.G. and Bai, R.J. (2003)’Organizational mechanism for successful IS/IT strategic planning in the digital era', Management Decision, Vol. 41, No. 1, pp.32-42.

Lee, G.G. and Gough, T. (1993) 'An integrated framework for information systems planning and its initial application', Journal of Information Technology, Vol. 8, pp.227-240.

Mentzas, G. (1997) 'Implementing an IS strategy - a team approach', Long Range Planning, Vol. 30, No. 1, pp.84-95.

Newman, M. and Sabherval, R. (1996) 'Determination of commitment to information systems development: a longitudinal investigation’, MIS Quarterly, March, pp.23-54.

Niederman, F., Brancheau, J.C. and Wetherbe, J.C. (1991) 'Information systems management issues for the 1990s', MIS Quarterly, Vol. 17, No. 4, pp.475-500.

Pai, J.C. (2006) 'An empirical study of the relationship between knowledge sharing and IT/IS strategic planning (ISSP)’, Journal of Management Decision, Vol. 44, No. 1, pp.105-122.

Premkumar, G. and King, W.R. (1994) 'The evaluation of strategic information systems planning', Information and Management, Vol. 26, pp.327-340.

Raghunathan, B. and Raghunathan, T.S. (1994) 'Adaptation of a planning system success model to information systems planning’, Information System Research, Vol. 5, No. 3, pp.326-340.

Reponen, T. (1993) 'Strategic information systems - a conceptual analysis', Journal of Strategic Information Systems, June, Vol. 1, No. 2, pp.100-104.

Sabherwal, R. and King, W.R. (1995) 'An empirical taxonomy of the decision-making processes concerning strategic applications of information systems', Journal of Strategic Information Systems, Vol. 11, No. 4, pp.177-214.

Segars, A.H. and Grover, V. (1998) 'Strategic information systems planning success: an investigation of the construct and its measurement', MIS Quarterly, June, pp.139-163.

Sherer, S.A. (2004) 'IS projects selection: the role of strategic vision and IT governance', Proceeding of the 37th Hawaii International Conference on System Sciences, USA. 
Tai, L.A. and Phelps, R. (2000) 'CEO and CIO perceptions of information systems strategy: evidence from Hong Kong’, European Journal of Information Systems, Vol. 9, pp.163-72.

Teo, T.S.H. and Ang, J.S.K. (1999) 'Critical success factors in the alignment of IS plans with business plan’, International Journal of Information Management, Vol. 19, pp.173-185.

Teo, T.S.H. and Ang, J.S.K. (2000) 'How useful are strategic plans for information systems?', Behaviour and Information Technology, Vol. 19, No. 4, pp.275-282.

Turban, E., Dorothy, E.L., McLean, E.R. and Wetherbe, J.C. (2003) Information Technology for Management: Transforming Organizations in the Digital Economy, John Wiley \& Sons, New York, NY.

Wang, E.T.G. and Tai, J.C.F. (2003) 'Factors affecting information systems planning effectiveness: organizational context and planning systems dimensions', Information \& Management, Vol. 40, pp.287-303.

Ward, J. and Peppard, J. (2002) Strategic Planning for Information Systems, 3rd ed., Chapter 1, John Wiley \& Sons, New York, NY.

Watson, R.T., Kelly, G.G., Galliers, R.D. and Brancheau, J.C. (1997) 'Key issues in information systems management: an international perspective', Journal of Management Information Systems, Vol. 13, No. 4, pp.91-115.

\section{Appendix}

1 Organisational factors

a Non-cooperative organisational factors

i Organisational commitment - adapted from Basu et al. (2002)

Sufficient resources were allocated to the SISP study

ORCM1

SISP study leaders and sponsors had high credibility

ORCM2

Key people stayed on the SISP study from its start to

ORCM3

finish to maintain continuity

Management controlled the SISP study closely enough

ORCM4

to resolve conflict among different organisational subunits

ii Change management - adapted from Lee and Bai (2003)

Top management were educated about the importance

CHMG1

of IT strategic plan

Organisation's personnel were educated about the

CHMG2

importance of IT strategic plan

Various functional managers were involved in IT

CHMG3

strategic planning process

Organisation's personnel were involved in some parts

CHMG4

of IT strategic planning process

iii IS maturity - adapted from Bai and Lee (2003)

IT is perceived in the company as important and able to make a significant impact

Top management's knowledge about information technology

ISMA2

IS planning takes the company's business plan into consideration

ISMA3 
Information technology is available throughout the company

ISMA4

premises

Information technology supports various functions in the

ISMA5

company

b Cooperative organisational factors

i Senior management involvement - adapted from Basu et al. (2002)

A top executive championed the SISP study

SMGT1

The planning team determined senior management's key

SMGT2

planning issues at the start of the project

The planning team briefed senior management with the SISP

SMGT3

study's scope, objectives, and approaches to gain its commitment at the project's start

The planning team briefed senior management throughout the project to maintain its commitment

Senior management provided feedback and guidance throughout

SMGT5 the SISP study

ii Team involvement - adapted from Basu et al. (2002)

Inputs were solicited from the organisational levels responsible for implementing the SISP plan

The planning process contains various level of management

TEAM1

Team members were educated about the scope and goals of the

TEAM2

project, the organisation's mission and purpose, and its internal

TEAM3

and external environment

Team members were trained in the SISP methodology

TEAM4

iii CIO and CEO relationship - adapted from Bai and Lee (2003)

CEO frequently communicates with the CIO for the IS plan

CICE1

CIO spends time educating CEO about IS opportunities and

CICE2 threats

CEO relies on CIO for information about MIS needs

CICE3

Interviews-in-depth existed between CIO and CEO

CICE4

2 IT strategic planning dimensions

a Strategic alignment - adapted from Segars and Grover (1998)

Understanding of top management about the role of IS as enabler ALIN1

for business strategies and two-way relationship between them

Compatibility between IS goals and business changing goals

ALIN2

Identifying IT-based opportunities for supporting business

ALIN3

strategies

Compatibility between technology and organisation's strategic

ALIN4 changes

Assessing the organisational importance of new technologies 
b Environmental assessment - adapted from Wang and Tai (2003)

Internal capabilities

INEA1

Past performance

INEA2

Reasons for past failures

INEA3

General economic and business trends

EXEA1

Regulatory issues

EXEA2

Worldwide competition

EXEA3

Customer/end user preferences

EXEA4

Technological trends

EXEA5

3 IT strategic planning success (efficiency) - adapted form Segars and Grover (1998), Premkumar and King (1994), and Basu et al. (2002)

Align information technology with business needs

ISPS1

Gain a competitive advantage from information technology

ISPS2

Identifying opportunities fro internal improvement in business

ISPS3 process through IT

Forecast information technology resource requirements

Development of a company-wide information architecture

ISPS5

Identifying and prioritising organisation's strategic IS

ISPS6 